\title{
POLLUTION-BASED MODEL PREDICTIVE CONTROL OF COMBINED SEWER NETWORKS, CONSIDERING UNCERTAINTY PROPAGATION
}

\author{
MAHMOOD MAHMOODIAN ${ }^{1}$, ORIANNE DELMONT $^{2} \&$ GEORGES SCHUTZ $^{3}$ \\ ${ }^{1}$ Luxembourg Institute of Science and Technology (LIST), Luxembourg. \\ ${ }^{2}$ Centre de Recherche en Automatique de Nancy (CRAN), France. \\ ${ }^{3}$ RTC4Water, Luxembourg
}

\begin{abstract}
In this paper, two types of controllers are proposed and compared to attain a better understanding of the potential of a real-time control (RTC) approach based on wastewater quantity and quality for combined sewer networks. The first controller is solely based on a wastewater quantity control approach, whilst, the second one is also considering wastewater quality modelling, as well as its uncertainty propagation. In fact, we have developed the first controller to achieve the second one without the requirement of adding new measurement devices to the given system. Model Predictive Control (MPC) approach is selected as the underlying control method. The control model in this study is a simple but fast model which is developed based on volume balance and mass balance laws in the tanks and time delay concept in the pipes. This model is described and applied to a simple case study to illustrate and discuss the results. The uncertainty propagation in the second controller is based on Taylor series of first order approximation. Based on the simulations and the achieved results, it was observed that the introduced pollution-based MPC approach is able to reduce significantly the volume of combined sewer overflows (CSOs) as well as the pollution load caused by them. Finally, it is concluded that considering the pollution load and its uncertainty propagation in the objective function of the optimization problem has a significant effect on the system performance improvement. This is a very important achievement because it can reduce the released pollution load to the environment without the requirement of additional equipment in the system. Because such elements (e.g. sensors) are normally expensive to purchase and maintain.
\end{abstract}

Keywords: combined sewer overflow (CSO), model predictive control (MPC), real-time control (RTC), uncertainty propagation, wastewater quality.

\section{INTRODUCTION}

Real-time control (RTC) of urban drainage systems to improve their efficiency and performance has become an active area of research in recent years, see [1-3]. This fact is not only because these systems are essential for human health, but also as a result of increased requirements regarding the environmental and economic considerations [4, 5].

Combined sewer networks are smoothly capable of handling the wastewater produced from the dwellings during the dry weather flow (DWF) while there is no rainfall in the catchment. However, the problem arises when a long or heavy rainfall occurs and the rain water combines with the DWF and produces wet weather flow (WWF). In this situation, the capacity of network pipes and storage tanks may not be sufficient to store the wastewater before passing it to the wastewater treatment plant (WWTP). Consequently, some part of the excess untreated wastewater, which is referred as combined sewer overflow (CSO), will be released to the surrounding environment. This event increases the pollution risk of the receiving water 
bodies and complicates the sewer network management. Proper modelling and effective RTC of storage tanks in the sewer networks before the treatment plants has a great importance to deal with this problem. Hence, quality-based RTC for the urban drainage systems should be taken into account more seriously, see [5-8].

In this paper, it has been tried to introduce a methodology for RTC of the combined sewer networks using a simple tank-based model. First, a quantity-based model is introduced. Consequently, this model is developed to consider wastewater quality. These models are employed as the control models in an MPC approach for RTC. Quantitative and qualitative objective functions and the constraints are presented in the next step. A simple uncertainty propagation method for wastewater quality modelling is also introduced in this paper, which is going to be considered in the qualitative objective function. Finally, the developed controllers are implemented for a simple case study and the main results are presented and discussed briefly.

\section{METHOD}

\subsection{Control model}

Control model in MPC approach is normally a simple and fast model which simulates the general behavior of the system according to our interests in controlling the given system. In this study, the control model has been evolved during the progress of the research. Initially, a simple model was developed for wastewater quantity control which has been in operation in Luxembourg Institute of Science and Technology (LIST) for some years. In this paper, the former model is expanded to consider wastewater quality as well. In the following paragraphs these two control models are briefly explained.

\subsubsection{Simple wastewater quantity model}

In this section, the concept of the simple tank model used for quantity modelling of the wastewater in the network is described. This model is based on conservation of volume in the tank. Figure 1 shows the involved system variables of the model.

Each tank contains a wastewater level sensor which gives the water level (h) in the tank. By taking advantage of this measurement and considering the geometry of the tank, one can calculate the volume of stored wastewater in the tank $\mathrm{V}$. The volume is controlled by a valve or pump at the outlet of the tank, thereby controlling the outflow, $\mathrm{Q}_{\text {out }}$, which is measured.

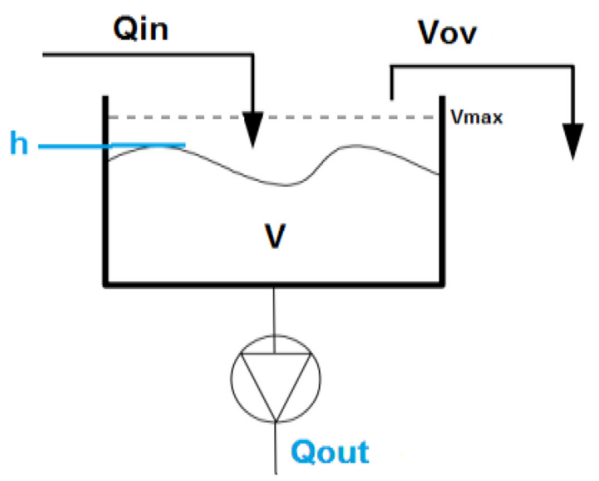

Figure 1: System variables of the tank model for wastewater quantity modelling. 
However, the inflow to the tank $\mathrm{Q}_{\mathrm{in}}$ is not measured, but it can be derived from the law of conservation of volume in the tank:

$$
V(t)=V(t-\Delta t)+Q_{\text {in }}(t) \Delta t-Q_{\text {out }}(t) \Delta t-V_{\text {ov }}(t)
$$

$\mathrm{Q}_{\text {in }}$ and $\mathrm{Q}_{\text {out }}$ are supposed constant over $\Delta t$. Thus, we find that:

$$
Q_{\text {in }}(t)=\left(\frac{V(t)-V(t-\Delta t)-V_{\text {ov }}(t)}{\Delta t}\right)+Q_{\text {out }}(t)
$$

In case of having a CSO event, $V_{o v}>0$, otherwise $V_{o v}=0$. The overflow volume is calculated based on a simple technique by considering a tank with known geometry and an infinite height. If $h$ is higher than $h_{\max }$, the excess volume is calculated as the overflow volume as a function of $\left(\mathrm{h}-\mathrm{h}_{\max }\right)$.

Since the sewer system is a combined one, the incoming flow is a combination of the wastewater flow from the dwellings $\mathrm{Q}_{\mathrm{DW}}$ and the flow from the rain water $\mathrm{Q}_{\mathrm{WW}}$ :

$$
Q_{\text {in }}(t)=Q_{D W}(t)+Q_{W W}(t)
$$

In this approach, we consider that $\mathrm{Q}_{\mathrm{DW}}$ has a daily pattern for each tank in the network. For the tanks in our case study these patterns are available. Therefore, the amount of $\mathrm{Q}_{\mathrm{WW}}$ can be easily calculated by subtracting the $\mathrm{Q}_{\mathrm{DW}}$ from $\mathrm{Q}_{\mathrm{in}}$ measurement. It should be noted that, for $\mathrm{Q}_{\text {in }}$ there are measurement campaigns available for our case study tanks as well.

In this quantitative modelling, the flow in the pipelines of the network is modelled using the delay time concept (see Fig. 2). Hence, for the simple model introduced in this paper, it would be beneficial to have an idea about the amount of delay time between different tanks in the sewer network.

\subsubsection{Extension to a simple wastewater quality model}

To better understand the system variables of the tank in this model, the Fig. 3 is modified as follows:

Here, we make three main assumptions: there is only one global indicator to reflect the pollution load; there is only a simple dilution effect in the tank; and the concentration ' $\mathrm{C}$ ' of

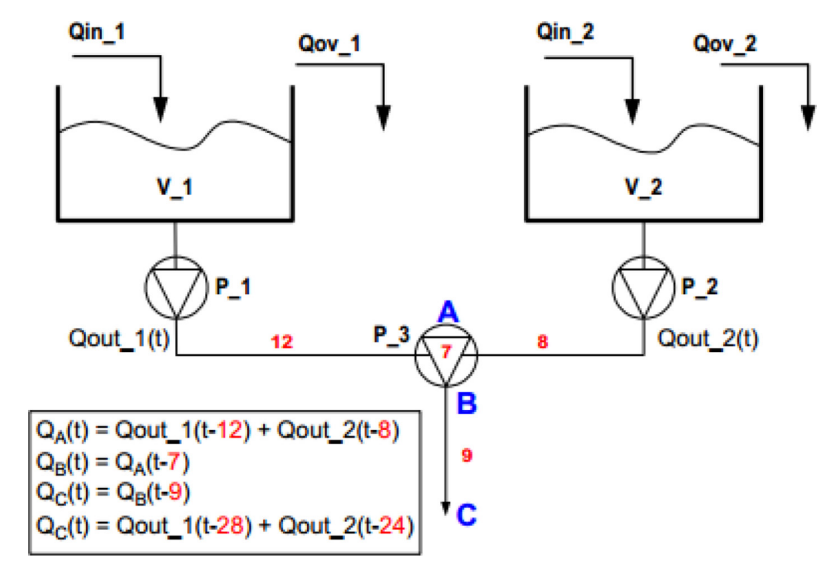

Figure 2: Time delay concept used in the network modelling. 


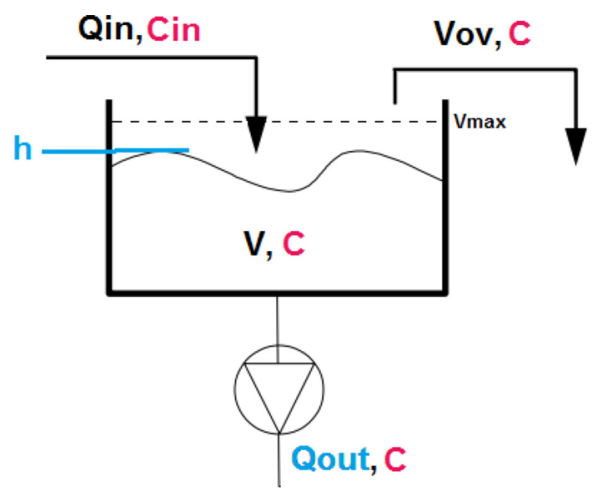

Figure 3: System variables of the tank model for wastewater quality modelling.

the pollutant load in the tank is homogeneous. Hence, by taking into account the eqn (1) and the mass balance law, we have: (m represents the pollutant load mass).

$$
m(t)=m(t-\Delta t)+m_{\text {in }}(t)-m_{\text {out }}(t)-m_{\text {ov }}(t)
$$

We assume that the concentration ' $\mathrm{C}$ ' exiting the tank, either by the outlet valve or in case of a CSO, is the same as the one inside the tank. From eqn (4) we obtain:

$$
\begin{aligned}
C(t) V(t)= & C(t-\Delta t) V(t-\Delta t)+C_{\text {in }}(t) Q_{\text {in }}(t) \Delta t \\
& -C(t-\Delta t) Q_{\text {out }}(t) \Delta t-C(t-\Delta t) V_{\text {ov }}(t)
\end{aligned}
$$

Using this eqn (5) and substituting eqn (1) in it, one can achieve the equation for the concentration of pollutants in the tank:

$C(t)=\frac{C(t-\Delta t) V(t-\Delta t)+C_{\text {in }}(t) Q_{\text {in }}(t) \Delta t-C(t-\Delta t) Q_{\text {out }}(t) \Delta t-C(t-\Delta t) V_{\text {ov }}(t)}{V(t-\Delta t)+\left[Q_{\text {in }}(t)-Q_{\text {out }}(t)\right] \Delta t-V_{\text {ov }}(t)}$

It needs to be mentioned that, in this modelling step there should not be any changes on the real network for the purpose of quality-based RTC. It means, there is no need to add new sensors to the real system for the purpose of quality measurement in the tanks. Thus, the concentration of the global quality indicator in the tank is completely simulated and therefore uncertain. The uncertainty propagation for the concentration of the load in the tank is briefly discussed in the following section.

\subsection{Uncertainty propagation}

By definition a model is an abstraction of the reality. Models rarely resemble the real world behavior perfectly, because of abstracting the information about the system and this fact causes the uncertainty Warmink et al. [9]. Hence, any departure from the unachievable ideal of complete determinism is defined as uncertainty Walker et al. [10]. Hence, there is a crucial requirement to analyze the uncertainty in any modelling process to achieve robust decisions Refsgaard et al. [11]. Warmink introduces a structured procedure for the identification and classification of uncertainties in environmental models [9]. A brief review of 14 different methods for uncertainty assessment and characterization is addressed in [11]. The next 
paragraphs focus on understanding the behavior of the aforementioned unmeasured, uncertain variable which is the pollutant load concentration in the network structures. This is done by applying an uncertainty propagation approach for the introduced simple quality model.

In 1996, a study on uncertainty propagation in urban rainfall-runoff models was proposed by Lei [12]. Three main methods of uncertainty propagation are described in that study including sensitivity analysis, Monte Carlo method and Taylor series or first order approximation. These methods are still among the most common approaches in the field of sewer networks, see $[5,6]$.

In this study, we have selected the Taylor method (first order), because the qualitative model, although not linear, is differentiable. Besides, through measures in the real system for each variable in our simple model there is an idea about the tolerance interval in which it is located.

Various simplifying assumptions have been made to simplify the calculations. In particular, we consider the different variables related to the concentration are not correlated. Thus, the Taylor series approximation of the concentration in the tank is written as:

$$
\operatorname{Var}(C(t))=U_{C(t)}^{2}=\sum_{i=1}^{6}\left(\frac{\partial C(t)}{\partial A_{i}}\right)^{2} U_{A_{i}}^{2}
$$

With:

$$
A_{1}=\mathrm{C}(\mathrm{t}-\Delta t), A_{2}=\mathrm{V}(\mathrm{t}-\Delta t), A_{3}=Q_{\text {in }}(\mathrm{t}), A_{4}=C_{\text {in }}(\mathrm{t}-\Delta t), A_{5}=Q_{\text {out }}(\mathrm{t}), A_{6}=V_{\text {ov }}(\mathrm{t}-\Delta t) .
$$

After calculations of various partial derivatives, we can make the following assumptions:

$\mathrm{V}(\mathrm{t}-\Delta t)$ and $\mathrm{Q}_{\text {out }}(\mathrm{t})$ come from measurements and therefore have a measurement uncertainty. However, this uncertainty remains negligible compared to the uncertainties on $\mathrm{C}(\mathrm{t}-\Delta t)$ and $\mathrm{C}_{\mathrm{in}}(\mathrm{t}-\Delta t)$ that are unknown terms. So we can make the approximation that $\mathrm{U}_{\mathrm{V}(\mathrm{t}-\Delta t)}=\mathrm{U}_{\mathrm{Q}_{\text {out }}(\mathrm{t})}=0$.

Moreover, $V_{\mathrm{ov}}(\mathrm{t}-\Delta t)$ and $Q_{i n}(\mathrm{t})$ are deducted directly from previous measurements, so we can do the same approximation $\mathrm{U}_{V_{o v}(\mathrm{t}-\Delta t)}=\mathrm{U}_{\mathrm{Q}_{\text {in }}(\mathrm{t})}=0$.

Consider $\mathrm{U}_{\mathrm{X}}$ as the standard deviation of $\mathrm{X}$ such that variance of $\mathrm{X}$ is $\operatorname{Var}(\mathrm{X})=\mathrm{U}_{\mathrm{X}}{ }^{2}$. Then, the eqn (7) is:

$$
U_{C(t)}^{2}=U_{C(t-\Delta t)}^{2}(X(t-\Delta t))^{2}+U_{C_{i n}^{(t-\Delta t)}}^{2}(1-X(t-\Delta t))^{2}
$$

With:

$$
X(t-\Delta t)=\frac{V(t-\Delta t)-Q_{o u t}(t) \Delta t-V_{o v}(t)}{V(t)}=\frac{V(t)-Q_{\text {in }}(t) \Delta t}{V(t)}=1-\frac{Q_{\text {in }}(t) \Delta t}{V(t)}
$$

It is obvious that uncertainty propagation equation is strongly dependent on $\mathrm{X}(\mathrm{t}-\Delta t)$. Based on conservation of volume and the physical constraints of the model it can be easily proven that: $0 \leq X(t-\Delta t) \leq 1$.

For the choice of probability distribution laws associated with the concentration of the loads in the tank, the most commonly used ones are: the uniform uncertainty law (or rectangular) and the Gaussian law (or normal distribution).

In our case, the uniform distribution is selected because when a concentration value is unknown and unmeasured, it has the same probability that it actually lies in the interval $[-\mathrm{a} ; \mathrm{a}]$.

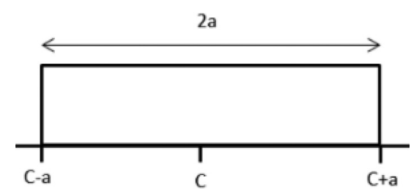


Hence, the standard deviation is $U_{X}=\frac{a}{\sqrt{3}}$ and the variance is $\operatorname{Var}(\mathrm{X})=\frac{a^{2}}{3}$

In terms of the standard deviation of the concentrations, the concentration $\mathrm{C}_{\mathrm{in}}$ entering the tank is decomposable in $\mathrm{C}_{\mathrm{DW}}$ and $\mathrm{C}_{\mathrm{WW}}$ (respectively the concentrations of wastewater during dry and wet weather). Therefore, on the same principle as eqn (3) and based on conservation of mass:

$$
C_{i n}(t)=\frac{C_{D W}(t) Q_{D W}(t)+C_{W W}(t) Q_{W W}(t)}{Q_{i n}(t)}=\frac{C_{D W}(t) Q_{D W}(t)+C_{W W}(t) Q_{W W}(t)}{Q_{D W}(t)+Q_{W W}(t)}
$$

Thus, by applying the same method of first order Taylor approximation and the same assumption on the uncertainty of flows, the propagation of uncertainty for the concentration of incoming load can be written as:

$$
U_{C_{i n}(t)}^{2}=U_{C_{D W}(t)}^{2}\left(\frac{\partial C_{i n}(t)}{\partial C_{D W}(t)}\right)^{2}+U_{C_{W W}(t)}^{2}\left(\frac{\partial C_{i n}(t)}{\partial C_{W W}(t)}\right)^{2}
$$

Finally, with the partial derivatives we have:

$$
U_{C_{i n}(t)}^{2}=U_{C_{D W}(t)}^{2}\left(\frac{Q_{D W}(t)}{Q_{i n}(t)}\right)^{2}+U_{C_{W W}(t)}^{2}\left(\frac{Q_{W W}(t)}{Q_{i n}(t)}\right)^{2}
$$

For calculation acceleration, we can make the approximation that the uncertainty of the concentration in the tank at the initial moment, is equal to the uncertainty of the incoming concentration: $U_{C}(0)=U_{C_{i n}}(0)$.

To summarize this section, with the introduced approach it is possible to calculate the uncertainty of the concentration of the load in the tank $U_{c}(\mathrm{t})$. This can be done by applying the eqns (8) and (12), and defining $U_{C}(0)$ as the initial value.

\subsection{Optimization problem}

RTC has various definitions in different fields of application. An urban wastewater network is considered to be controlled in real-time if the process variables are monitored in the given system and, (almost) at the same time, are used to operate actuators of the system during the flow process Schütze et al. [3]. As it was already mentioned, the RTC method used in this study is based on the MPC approach which employs an internal model (controller model) to forecast the behavior of a given system in future over a finite time horizon which is called prediction or control horizon. Taking the advantage of this prediction, MPC is able to prevent the undesired events that threaten the system. It presents the optimum control actions after solving an optimization problem Xu et al. [13]. Details of an MPC approach can be found in [14], an implementation in $\mathrm{MATLAB}^{\circledR}$ in [15] and more specifically related to wastewater systems can be seen in [16]. An optimization problem includes an objective function (O.F) and system constraints which are in fact the mathematical expression of the sewer network management objectives and physical system constraints. An O.F is normally a weighted aggregation of various goals according to the given optimization problem.

In this research, O.F has been evolved in two main steps along with the controller models. It initially was only including goals referring to quantity aspects of wastewater in the network. In the second step new goals are added to the previous O.F which are considering wastewater 
quality and uncertainty propagation aspects. O.Fs using both quantitative and qualitative goals are presented briefly in the sections (2.3.1 and 2.3.2). The model constraints are also introduced in section 2.3.3. The O.F is subject to minimization during the optimization task in MPC.

\subsubsection{Quantitative objectives}

The O.F with only quantitative goals was already developed by LIST and it was in operation since 2013, see [11, 12]. The main purpose was to optimize the output flow rate of each tank by minimizing the objective function $\mathrm{J}$, over the prediction horizon $\mathrm{H}_{\mathrm{p}}$. It represents a weighted aggregation of three goals, which is defined as follows:

In which:

$$
J=\sum_{n-t}^{t+H_{P}} \lambda \phi_{1}(n)+\beta \phi_{2}(n)+\alpha \phi_{3}(n)
$$

$\lambda, \beta, \alpha$ are the constants that enable weighting of the objectives to be preferred, and

$\mathrm{n}=\mathrm{t}+1, \ldots, \mathrm{t}+\mathrm{H}_{\mathrm{p}}$ are the time steps in the prediction horizon.

$\Phi_{1}$ is to use the storage capacity of the network homogenously. This is defined by the relative difference in volumes between the tanks.

$$
\phi_{1}(n)=\sum_{i=1}^{N}\left(V_{i}(n)-\frac{V_{i_{\max }}}{\sum_{j=1}^{N} V_{j_{\max }}} \sum_{k=1}^{N} V_{k}(n)\right)^{2}
$$

$\Phi_{2}$ is to keep the flow towards the WWTP as close as possible to the optimum operating reference value. It compares the inflow to the WWTP with its operating speed (reference value $\mathrm{y}_{\text {ref }}$ ).

$$
\phi_{2}(n)=\left(y_{\text {ref }}(n)-\sum_{i \in N_{k}^{*}} \operatorname{Out}_{i}\left(n-d_{i, k}\right)\right)^{2}
$$

$i=1 \ldots N$ is the number of tanks in the network and $j=1 \ldots N_{P}$ the number of pipes in the network. $d_{i, k}$ is the transport time of the $i^{\text {th }}$ tank to the destination tank $j$ ( $j=k$ representing the arrival at the treatment plant). $\mathrm{N}^{*}{ }_{\mathrm{j}}$ is all the tanks draining directly to the destination $\mathrm{j}$. $\Phi_{3}$ is assigned in the O.F to minimize the CSO volume.

$$
\phi_{3}(n)=\sum_{i=1}^{N}\left(O v_{i}(n)-N L\right)^{2}
$$

NL is a negative number and the purpose of introducing this value in $\Phi_{3}$ is to have a linear objective function, see Gillé et al. [17]. To process the overflow, we had to add a state variable $\mathrm{Ov}(\mathrm{t})$. Although, it is in fact directly related to the volume $\mathrm{V}(\mathrm{t})$ and the maximum volume $\mathrm{V}_{\max }$ of each tank.

\subsubsection{Qualitative objectives}

In this section, four new goals are added to the previous quantitative O.F based on the new state variables $\mathrm{C}_{\mathrm{i}}$ and according to the interests in how to control the network. The new O.F to be minimised is defined as follows:

$$
J=\sum_{n-t}^{t+H_{P}} \lambda \phi_{1}(n)+\beta \phi_{2}(n)+\alpha \phi_{3}(n)+\gamma \phi_{4}(n)+\mu \phi_{5}(n)+\sigma \phi_{6}(n)+\left(\frac{\delta}{\phi_{7}(n)}\right) s
$$


In which, $\Phi_{1}, \Phi_{2}$ and $\Phi_{3}$ are the same as before. $\gamma, \mu, \sigma$, and $\delta$ are the new constants to enable weighting of the objectives to be preferred in the O.F.

$\Phi_{4}$ is to minimize the overflowed mass.

$$
\phi_{4}(n)=\sum_{i=1}^{N}\left(C_{i}(n) O v_{i}(n)-N L\right)^{2}
$$

$\Phi 5$ is to minimize the uncertainty present in the concentration of the mass which is directly linked to the above mentioned goal $\Phi_{4}$.

$$
\phi_{5}(n)=\sum_{i=1}^{N}\left(U_{i}(n)-N L\right)^{2}
$$

By introducing this objective, in case that two tanks have the possibility of overflowing simultaneously, the controller prefers overflowing the tank with less uncertainty.

$\Phi_{6}$ is to distribute the pollutant mass over the network homogenously which is in fact similar to $\Phi_{1}$.

$$
\phi_{6}(n)=\sum_{i=1}^{N}\left(C_{i}(n) V_{i}(n)-\frac{V_{i_{\max }}}{\sum_{j=1}^{N} V_{j_{\max }}} \sum_{k=1}^{N} C_{k}(n) V_{k}(n)\right)^{2}
$$

$\Phi_{7}$ is to maximize the pollutant mass arriving at the WWTP. This goal resembles the goal $\Phi_{2}$ which was to deal with volumes arriving at the WWTP.

$$
\phi_{7}(n)=\left(\sum_{i \in N_{k}^{*}} C_{i}\left(n-d_{i, k}\right) O u t_{i}\left(n-d_{i, k}\right)\right)^{2}
$$

Since the objective $\Phi_{7}$ is to maximize the mass arriving at the WWTP and not to minimize it, the form $1 / \Phi_{7}$ is used in the objective function.

\subsubsection{Constraints}

All the inequality constraints describing the physical constraints on the system variables should be considered in MPC. The volume of wastewater in each tank, the outflow, and the wastewater contained in the pipes are all positive variables and limited by their maximum capacity:

$$
\begin{gathered}
0 \leq V_{i}(n) \leq V_{i_{\max }} \\
0 \leq O u t_{i}(n) \leq \text { Out }_{i_{\max }} \\
0 \leq O_{v}(n) \\
Q_{\text {pipe }_{j}}(n)=\sum_{i \in N_{J}^{*}} \operatorname{Out}_{k}\left(n-d_{i, k}\right) \leq Q_{\text {pipe }_{j_{\max }}}
\end{gathered}
$$

And for the new variables in the qualitative model, we have:

$$
0 \leq C_{i}(n) \text { and } 0 \leq U_{i}(n)
$$




\subsection{Case study}

The case study sewer network that has been selected for this paper is a small part of Haute-Sure catchment in northwest of Luxembourg. The original network consists of 24 storage tanks which are located upstream of a WWTP. In this study, only two of these storage tanks (Buderscheid and Kaundorf) are taken into account to test the developed RTC approaches.

For this case study, we have a model or pattern for concentration of wastewater arriving from the dwellings $\left(\mathrm{C}_{\mathrm{DW}}\right)$. The pattern is determined by measurement campaigns that were carried out for this catchment by Kai et al. $[18,19]$. Based on the knowledge and experience of the experts involved in the measurement campaigns, it is assumed that the uncertainty on this model or pattern is $\pm 5 \%$.

On the other hand, the concentration during the wet weather $\left(\mathrm{C}_{\mathrm{ww}}\right)$ is unknown. It is also estimated by a mean of the measurements on the real system. Here, it is assumed that the uncertainty on this value is $\pm 50 \%$ which, in fact, is a wide range of uncertainty. The average concentration during the wet weather is considered equal to $1,000 \mathrm{mg} / \mathrm{l}$ or $1 \mathrm{~kg} / \mathrm{m} 3$.

These values are selected only for initial demonstration of the method for this case study and cannot be generalized to other catchments.

In this case study, the weighting coefficients for the quantitative O.F were selected based on a previous work, see Gillé et al. [17]. These values are: $\lambda=1, \beta=1$; and $\alpha=5$. Whilst, for the qualitative O.F the weights were chosen based on trial and error, including: $\gamma=10$, $\mu=5, \sigma=1$, and $\delta=1$. It should also be noted that, the dimensionality of different goals in the O.F is considered in the optimization process. It means, for example, $\alpha=5$ and $\beta=1$ does not necessarily imply that $\Phi_{3}$ is five times more important than $\Phi_{2}$.

\section{RESULTS AND DISCUSSION}

Both of the developed MPC controllers were implemented for the introduced case study in MATLAB $^{\circledR}$. In case of quantitative O.F, the optimization task was done using CVX solver. But, since the qualitative model was not linear, the fmincon solver was used for the qualitative O.F. In this section, some of the main results for the two tanks in the case study are presented and compared to each other.

We are interested in understanding the behavior of our MPC controllers and their performance during the period in which an overflow occurs and the related pollution risk. Therefore, a part of a rain scenario from 18th October to 1st November 2002 were selected in which a measurement campaign exists in the real catchment (Fig. 4).

The results of applying the two developed controllers around the previously selected time period are illustrated in the following graph (see Fig. 5).

As it can be observed from Fig. 5, the volume behavior of the tanks for the quantitative controller seems very similar. To minimise the CSO volume $\left(\Phi_{3}\right)$, the maximum capacity of each tank is used. Homogenization of storage capacity in the network $\left(\Phi_{1}\right)$, forces both of the tanks to fill and deplete in the same pattern, therefore the CSO events occur almost in the same time. The objective for keeping the flow toward WWTP as close as the reference value $\left(\Phi_{2}\right)$ causes the depletion of the tanks.

On the other hand, for the qualitative controller, the volume behavior of the tanks is slightly different. For instance, the blue tank depletes faster in comparison with the former controller. This can be justified as a result of less importance of $\Phi_{1}$ compared to the new goals in the objective function. 


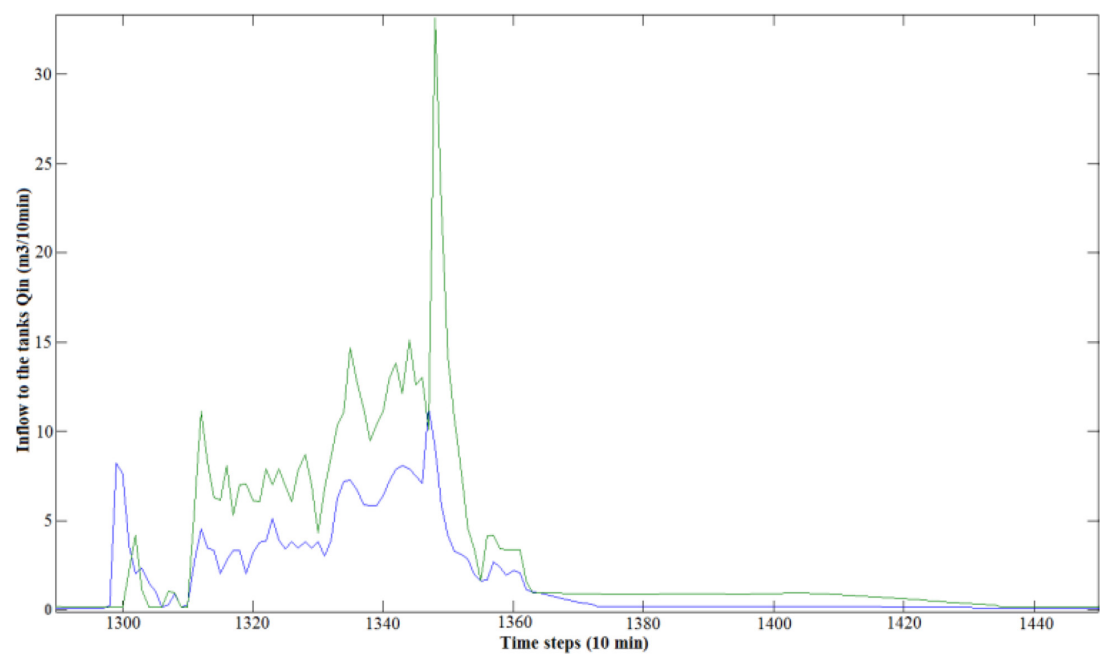

Figure 4: Measured inflow to the tanks during the October 2002 rain scenario (blue: Buderscheid tank; green: Kaundorf tank).
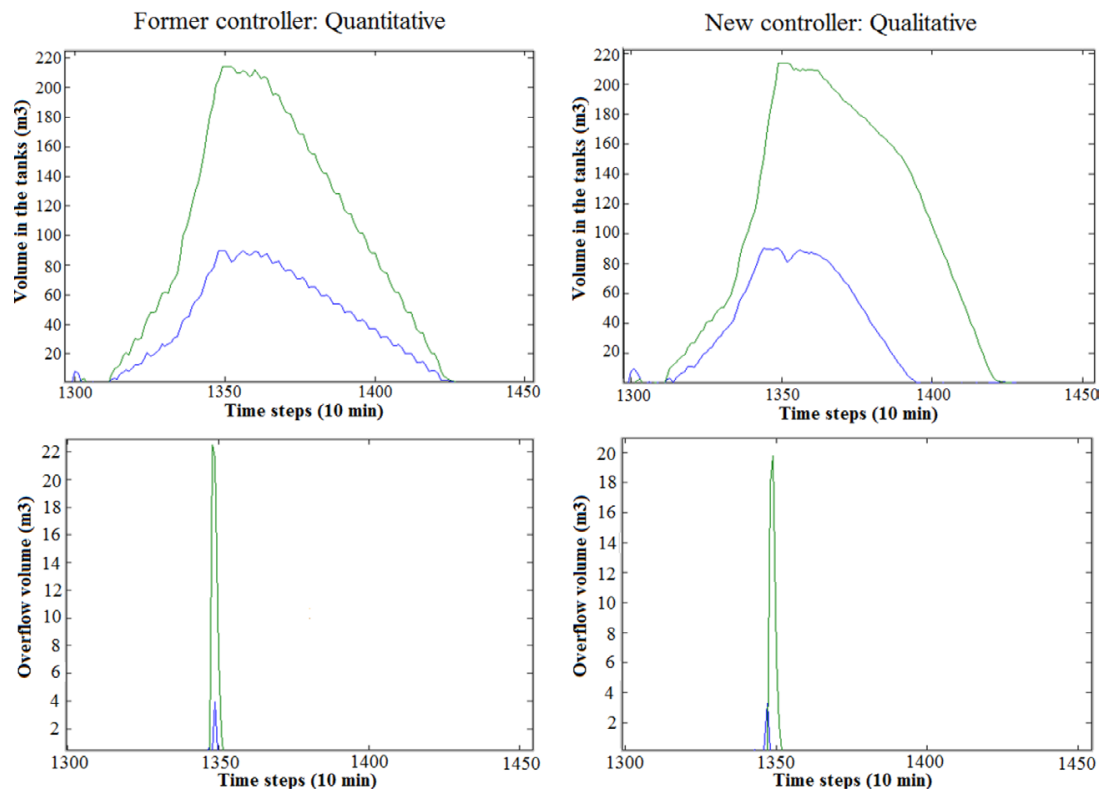

Figure 5: Comparing the controllers: quantitatively. (blue: Buderscheid tank; green: Kaundorf tank).

The "oscillations" on quantity-based controller curves mainly come from the $\Phi_{1}$. It is interesting that these curves are "smoothened" in the qualitative controller by the objective $\Phi_{6}$ for homogenization of loads in the network.

In the case of overflows, the main observation is that by introducing the new quality-based controller the CSO volume of green overflow has decreased, while the blue overflow occurs earlier in time with almost the same CSO volume. By adding the objective $\left(\Phi_{4}\right)$ for minimiz- 

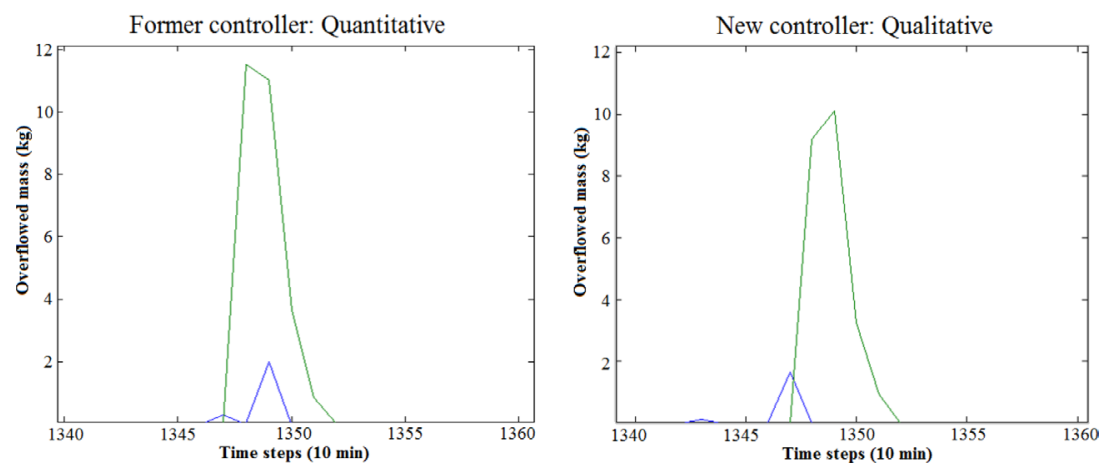

Figure 6: Comparing the controllers: qualitatively (blue: Buderscheid tank; green: Kaundorf tank).

Table 1: Comparison of the controllers based on overflow volume.

\begin{tabular}{ll}
\hline Former controller: Quantitative & New controller: Qualitative \\
\hline Overflow volume (Green): $52.8 \mathrm{~m}^{3}$ & Overflow volume (Green): $45.9 \mathrm{~m}^{3}$ \\
Overflow volume (Blue): $4.5 \mathrm{~m}^{3}$ & Overflow volume (Blue): $3.5 \mathrm{~m}^{3}$ \\
Total overflow volume: $57.3 \mathrm{~m}^{3}$ & Total overflow volume: $49.4 \mathrm{~m}^{3}$ \\
\hline
\end{tabular}

Table 2: Comparison of the controllers based on overflowed mass.

\begin{tabular}{ll}
\hline Former controller: Quantitative & New controller: Qualitative \\
\hline Overflowed mass (Green): $27 \mathrm{~kg}$ & Overflowed mass (Green): $23.5 \mathrm{~kg}$ \\
Overflowed mass (Blue): $2.3 \mathrm{~kg}$ & Overflowed mass (Blue): $1.8 \mathrm{~kg}$ \\
Total overflowed mass: $29.3 \mathrm{~kg}$ & Total overflowed mass: $25.3 \mathrm{~kg}$ \\
\hline
\end{tabular}

ing the overflowed mass, the overflow volume is reduced as well. Table 1 summarizes the overflow volumes in case of application of both controllers.

Based on the results shown in Table 1, it can be calculated that there is a $13.8 \%$ relative reduction in the total overflow volume by introducing the quality-based controller in our case study. This can be considered as a significant reduction if we take into account a larger and more extensive case study. Figure 6 and Table 2 illustrate the results in terms of overflowed mass in case of implementation of the different controllers.

According to the results presented in the Table 2, there is $13.6 \%$ relative reduction in the total overflowed mass by implementing the qualitative MPC controller which is a considerable reduction.

Regarding the uncertainty propagation objective, it was observed that, over time the term ${ }_{(t)}$ does not diverge, which was an encouraging result for the rest of the project. Although initially there was a high uncertainty on the concentration of the load and the input data, but over time it remained bounded.

From the results presented above, it can be concluded that, the new quality-based controller decreases the overflow volume as well as its pollutant mass. This fact can be explained by the goal $\Phi_{4}$ in the quality-based objective function which was assigned to decrease the 
overflowed mass. Since this objective is the product of overflow volume by its concentration, the solver decreases both of the product state variables to minimise this objective. However, other goals in the objective function could have an effect on this result as well. Therefore, it should not be considered as an individual effect of $\Phi_{4}$ and a clearer conclusion can be made based on further sensitivity analysis. Investigation on the interactions between various goals can also be of interest in further studies.

\section{CONCLUSIONS}

Initially, two simple models were introduced for the purpose of quantity- and quality-based control of combined sewer networks. These types of simple and fast models are always favourable in MPC approach. The main idea was to understand if the quality-based controller can improve the efficiency of the former quantity-based MPC controller. An uncertainty propagation method was also introduced for the unmeasured variable of pollution load in the tanks and included in the objective function of the quality-based controller.

In conclusion, the results showed a positive contribution of the new quality-based controller in decreasing the overflowed pollution mass as well as CSO volume during the selected rain scenario. In fact, this is a very promising result and can be considered as a 'soft' solution for combined sewer network management. Because, the new controller reduces the pollution load and overflow volume without the need to add new physical elements (e.g. sensors) to the system which are normally expensive to purchase and maintain.

\section{ACKNOWLEDGEMENT}

Mahmood Mahmoodian has received funding from the European Union's Seventh Framework Programme for research, technological development and demonstration under grant agreement no. 607000 (www.quics.eu).

\section{REFERENCES}

[1] Campisano, A.P., Creaco, E. \& Modica, C., Improving combined sewer overflow and treatment plant performance by real-time control operation. Enhancing Urban Environment by Environmental Upgrading and Restoration, 43, pp. 122-138, 2005. http://dx.doi.org/10.1007/1-4020-2694-3_11

[2] Fuchs, L., Günther, H. \& Lindenberg, M., Minimizing the water pollution load by means of real-time control - the dresden example. Proceeding 6th International Conference Urban Drainage Model, 2004.

[3] Schütze, M., Campisano, A., Colas, H., Schilling, W. \& Vanrolleghem, P.A., Real time control of urban wastewater systems-where do we stand today? Journal of Hydrology, 299(3-4), pp. 335-348, 2004. http://dx.doi.org/10.1016/S0022-1694(04)00375-0

[4] Dirckx, G., Schütze, M., Kroll, S., Thoeye, C., De Gueldre, G. \& Van De Steene, B., Cost-efficiency of RTC for CSO impact mitigation. Urban Water Journal, 8(6), pp. 367-377, 2011. http://dx.doi.org/10.1080/1573062X.2011.630092

[5] Langeveld, J.G., Benedetti, L., de Klein, J.J.M., Nopens, I., Amerlinck, Y., van Nieuwenhuijzen, A., Flameling, T., van Zanten, O. \& Weijers, S., Impact-based integrated real-time control for improvement of the Dommel River water quality. Urban Water Journal, 10(5), pp. 312-329, 2013.

http://dx.doi.org/10.1080/1573062X.2013.820332 
[6] Weinreich, G., Schilling, W., Birkely, A. \& Moland, T., Pollution based real time control strategies for combined sewer systems. Water Science Technology, 36(8-9), pp. 331-336, 1997. http://dx.doi.org/10.1016/s0273-1223(97)00577-5

[7] Schilperoort, R.P.S., Gruber, G., Flamink, C.M.L., Clemens, F.H.L.R. \& van der Graaf, J.H.L.R., Temperature and conductivity as control parameters for pollution-based realtime control. Water Science Technology, 54(11-12), pp. 257-263, 2006. http://dx.doi.org/10.2166/wst.2006.744

[8] Lacour, C. \& Schutze, M., Real-time control of sewer systems using turbidity measurements. Water Science Technology, 63(11), pp. 2628-2632, 2011. http://dx.doi.org/10.2166/wst.2011.159

[9] Warmink, J.J., Janssen, J.A.E.B., Booij, M.J. \& Krol, M.S., Identification and classification of uncertainties in the application of environmental models. Environmental Model Software, 25(12), pp. 1518-1527, 2010. http://dx.doi.org/10.1016/j.envsoft.2010.04.011

[10] Walker, W.E., Harremoes, P., Rotmans, J., Van Der Sluijs, J.P., Van Asselt, M.B., Janssen, P. \& Krayer Von Krauss, M.P., A conceptual basis for uncertainty management. Integrated Assessment, 4(1), pp. 5-17, 2003. http://dx.doi.org/10.1076/iaij.4.1.5.16466

[11] Refsgaard, J.C., van der Sluijs, J.P., Højberg, A.L. \& Vanrolleghem, P.A., Uncertainty in the environmental modelling process - a framework and guidance. Environment Model Software, 22(11), pp. 1543-1556, 2007. http://dx.doi.org/10.1016/j.envsoft.2007.02.004

[12] Lei, J.H., Uncertainty Analysis of Urban Rainfall-runoff Modelling, NTNU: Trondheim, Norway, 1996.

[13] Xu, M., van Overloop, P.J. \& van de Giesen, N.C., Model reduction in model predictive control of combined water quantity and quality in open channels. Environmental Modelling Software, 42, pp. 72-87, 2013. http://dx.doi.org/10.1016/j.envsoft.2012.12.008

[14] Fallis, A., Model predictive control, 53(9), 2013.

[15] Wang, L., Model Predictive Control System Design and Implementation Using MATLAB ${ }^{\circledR}$, Springer, Australis, 2009.

[16] Ocampo-Martinez, C., Model Predictive Control of Wastewater Systems, 2010. http://dx.doi.org/10.1007/978-1-84996-353-4

[17] Gillé, S., Fiorelli, D., Henry, E. \& Klepiszewski, K., Optimal operation of a sewer network using a simplified hydraulic model. In 11th International Conference on Urban Drainage, Edinburgh, Scotland, UK, 2008.

[18] Seiffert, S. \& Klepiszewski, K., Haute-Sure Catchment Measurement Campaigns, Luxembourg Institute of Science and Technology (LIST): Belvaux, 2011.

[19] Regneri, M., Modeling and multi-objective optimal control of integrated wastewater collection and treatment systems in rural areas based on fuzzy decision-making. doctoral thesis at Technischen Universität Graz, 2014.

[20] Vezzaro, L., Christensen, M.L., Thirsing, C., Grum, M. \& Mikkelsen, P.S., Water quality-based real time control of integrated urban drainage systems: a preliminary study from Copenhagen, Denmark. Procedia Engineering, 70, pp. 1707-1716, 2014. http://dx.doi.org/10.1016/j.proeng.2014.02.188 
[21] Cabane, P., Incertitudes associées à l'estimation des rejets de temps de pluie des réseaux d'assainissement unitaires, Thèse de Doct. Génie Civil, Lyon: Institut National des Sciences Appliquées de Lyon, 2001.

[22] Garcia Salas, J.C., Evaluation des performances, sources d'erreur et incertitudes dans les modèles de déversoirs d'orage. Thèse de Doct. Génie Civil, Lyon: Institut National des Sciences Appliquées de Lyon, 2003.

[23] Fiorelli, D. \& Schutz, G., Real-time control of a sewer network using a multi-goal objective function. IEEE Proceeding 17th Mediterranean Conference on Control and Automation, pp. 676-681, 2009. http://dx.doi.org/10.1109/med.2009.5164621

[24] and G. S. D. Fiorelli, "Sensitivity of an optimal controller of a combined sewer system to the influent flows forecasting accuracy." In 7th international conference on sustainable techniques and strategies in urban water management (Novatech 2010), 2010. 